\title{
ENTRE LA NECESIDAD Y EL AZAR. NUEVOS DATOS PARA EL ESTUDIO DE LA OBRA DE CRISTÓBAL HALFFTER ENTRE 1957 Y 1962*
}

Germán Gan Quesada

Universitat Autònoma de Barcelona

ORCID: https://orcid.org/0000-0002-0522-7138

\section{RESUMEN}

Entre 1957 y 1962, el compositor madrileño Cristóbal Halffter (1930) participó plenamente del proceso de renovación de la composición musical española y lideró, en muchos aspectos, el inicio de su proyección internacional. Por medio de la recuperación de fuentes primarias hasta ahora inéditas -y a partir de la consulta preferente de su colección personal, conservada en la Paul Sacher Stiftung de Basilea-, este artículo ofrece nuevos materiales sobre algunas de las obras más significativas de ese período (Introducción, fuga y final, Sonata para violín solo, 5 microformas para orquesta, Formantes e In exspectatione resurrectionis Domini), como contribución a la reevaluación del repertorio musical español de vanguardia del segundo franquismo.

Palabras clave: Cristóbal Halffter, música española de vanguardia, estética musical, estructura sonora, aleatoriedad controlada

\section{ABSTRACT}

Between 1957 and 1962, the composer Cristóbal Halffter (Madrid, 1930) played an integral part in updating Spanish musical composition and spearheaded its dissemination worldwide. In recovering a large number of primary sources, which have yet to be discussed, and, in particular, referring extensively to the composer's personal collection - held at the Paul Sacher Stiftung in Basel - this essay offers up new material on some of Halffter's most significant compositions in this period (Introducción, fuga y final, Sonata para violín solo, 5 microformas para orquesta, Formantes, and In exspectatione resurrectionis Domini). It also provides a preliminary insight into their relevance to a forthcoming reevaluation of the historical, technical, and aesthetic features of the Spanish avant-garde repertoire in the middle years of the Franco regime.

Keywords: Cristóbal Halffter, Spanish avant-garde music, music aesthetics, musical structures, controlled aleatoricism

\section{Introducción}

"La música española parece haber entrado, hoy, en un período de estancamiento" ". Aunque tan terminante opinión, escrita hacia 1960, se refería fundamentalmente a la actividad de las generaciones de compositores españoles que, anclados en un paradigma estilístico de horizontes neoclasicistas y posnacionalistas, proseguían su actividad en ese momento, su autor -con toda probabilidad Luis de Pablo, encubierto bajo el seudónimo 'Musicus'²-, no dejaba en páginas posteriores de sostenerla parcialmente para juzgar la ambigüedad, o al menos incertidumbre, estética que descubría en las aportaciones de una 'nueva generación' que, desde mediados del decenio de 1950, pugnaba por actualizar la creación 

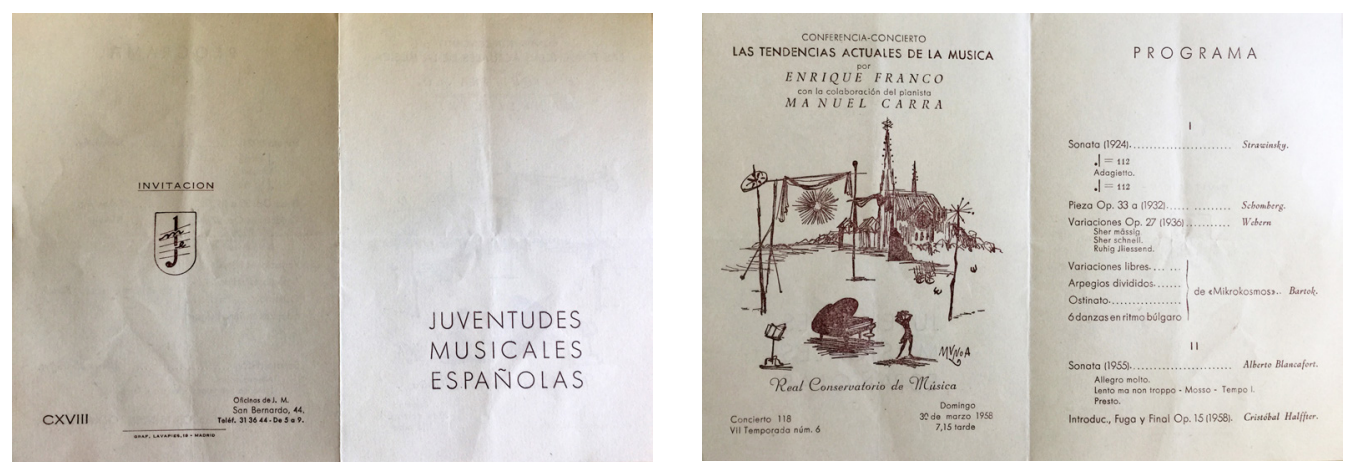

Fig. 1 a y b. Programa de concierto del estreno de la Introducción, fuga y final (Madrid, 30 de marzo de 1958) (Col. Particular)

musical de nuestro país y por inscribirla dentro de las coordenadas generales que otro de esos jóvenes músicos, José Luis de Delás, sintetizaba en octubre de 1959 en esta dicotomía:

De hecho se observa la aparición de una tendencia en la que coexisten y contrastan elementos constructivos y aleatorios, no sólo en el proceso de creación sino también en el de realización interpretativa $^{3}$

Desde los primeros acercamientos panorámicos a este fenómeno ${ }^{4}$ hasta contribuciones monográficas más recientes ${ }^{5}$, la musicología española ha prestado sobrada atención al desencadenamiento, evolución y marco cultural e institucional de este proceso general; tampoco faltan, obviamente, estudios particulares sobre el papel jugado en él por uno de sus principales protagonistas, el compositor madrileño Cristóbal Halffter (1930) ${ }^{6}$, en un período -que en este texto se acota entre los años 1957 y 1962- decisivo para la gestación de sus prácticas de vanguardia y para la consecución de una anhelada proyección internacional de su catálogo.

Sin embargo, y pese a este sostenido interés historiográfico, aún falta un balance crítico y actualizado que permita una valoración global de las múltiples líneas de fuerza que caracterizan la creación musical española de vanguardia en el decenio de 1960; una valoración, en suma, que amplíe, matice o corrija afirmaciones y premisas consolidadas en su interpretación y que permita rescatar del olvido -en términos, por ejemplo, de su presencia en programaciones musicales y de su recuperación discográfica- el repertorio creado durante esos años sobre el que se sustentan tales aseveraciones. El afloramiento de nuevas fuentes aún no cotejadas y la necesidad de una mirada directa, y hasta cierto punto 'ingenua', sobre los documentos primarios, tanto sonoros como escritos, posibilitan y guían este texto, que también ofrece algunas intuiciones (que no resultados definitivos) analíticas y aprovecha los fondos del archivo personal de Cristóbal Halffter (Paul Sacher Stiftung - Sammlung Cristóbal Halffter, en adelante PSS-SCH), especialmente a raíz del trabajo de ordenación e inventario, desarrollados por quien firma entre 2014 y 2017, de su colección epistolar, hasta este momento apenas explorada.

\section{En el umbral incierto de la vanguardia (1957-1959)}

Los caminos hacia la vanguardia, y no solo en el caso de Halffter, fueron sinuosos: esa 'tendencia constructiva' orientada hacia la modernidad de la que hablaba Delás coexiste en su catálogo de finales de los años cincuenta, de hecho, con obras en las que el resabio neoclasicista o la huella folklorizante domina sin atisbo de duda. Páginas como la Partita para violonchelo y orquesta (1957/58)7, el Himnum [sic] heroicum panegyricum [op. 19] (1958/59), la música incidental para La Orestíada (1959) o, sobre todo, el ballet Jugando al toro [op. 21] , estrenado en el Liceo barcelonés en abril de 1960, son prueba de dicha coexistencia, que hasta cierto punto se corresponde con la naturaleza transitiva de esta etapa de la producción halffteriana.

Incluso composiciones en que, desde un punto de vista melódico-armónico, la opción por vo- 
cabularios y estrategias dodecafónicos apostaba por una vía más decidida, la conformación estructural se amparó, en muy buena medida, en modelos tradicionales. Así, una obra como la Introducción, fuga y final [op. 15] (1957), para piano -más allá de las resonancias franckianas o regerianas de su título"-, muestra claramente el sometimiento de morfologías sonoras dodecafónicas ortodoxas a moldes sintácticos barrocos, a lo que habrían de sumarse elementos rítmicos -como el uso de ritmos pointés, el carácter de giga de la fuga o el espíritu de toccata final-que acentúan una vinculación no desmentida por el propio compositor al referirse a las reverberaciones bachianas omnipresentes en la obra ${ }^{10}$. La experiencia de Halffter en el repertorio barroco era amplia desde los inicios de su actividad como director de orquesta en 1952; pero tampoco debería obviarse el posible peso como precedente de soluciones similares anteriores en la propia genealogía dodecafónica -así, la Suite op. 25 (1921/23), de Arnold Schönberg- o, como ya indicara Enrique Franco en 1960, la huella del 'neobachianismo' de Paul Hindemith", una impronta que, muy probablemente a propósito de esta Introducción, fuga y final, llevaría a Roberto Gerhard a motejar a Halffter de "progresista a lo Hindemith" en su valoración de la obra del compositor madrileño' ${ }^{12}$.

Introducción, fuga y final, estrenada por Manuel Carra a fines de marzo de 1958 en el conservatorio madrileño (fig. 1), constituyó también (Madrid, Ateneo, 8 de abril de 1958) la carta de presentación de Halffter en las actividades públicas del grupo 'Nueva Música', conformado pocos meses antes. Aunque sea cierto -como señaló 'Musicus' en el texto que aducíamos al comienzo de la introducción- que no acertaba a extraer las implicaciones formales y tímbricas que requería una comprensión consciente de la técnica serial dodecafónica ${ }^{13}$, también lo es que, junto a la Sonata (1958), de Luis de Pablo, y el Preludio, diferencias y toccata sobre un tema de Isaac Albéniz (1959), de Manuel Castillo, ha mantenido cierta vigencia en el reducido repertorio pianístico español 'moderno' de esos años difundido en la actualidad; y que el propio Halffter la juzgaba suficientemente representativa del momento de su evolución estilística como para incluirla en la primavera de 1959 en la selección de obras presentadas a las editoriales italianas Ricordi y Suvini Zerboni para incorporarse a sus catálogos editoriales ${ }^{14}$.

La infructuosa conciliación entre principios estructurales tradicionales y organización y tratamiento de alturas dodecafónico es también visible en obras poco posteriores a esta Introducción, fuga y final. Quizá la asistencia -a la que finalmente hubo de renunciar- a los Internationale Ferienkurse für Neue Musik de Darmstadt de 1958 (en los que, por ejemplo, Ernst Krenek disertó sobre "Nuevas posibilidades de aplicación del principio serial"15), hubiera podido llevar a Halffter a soluciones más maduras e integradoras que las que muestra la Sonata para violín solo [op. 20], fechada en abril de 1959. "Obra puente" o hito divisorio en el catálogo del compositor ${ }^{16}$, la op. 20 de Halffter parte-con la ampliación del primer movimiento, reelaboración de los movimientos centrales y adición del movimiento conclusivo- de las dos meses anteriores Tres piezas para flauta sola [op. 18]; y si bien en ese proceso de reescritura se omitieron algunos rasgos que enfatizarían su conexión con la Introducción... ${ }^{17}$, no faltan otros que, recogidos por exégetas posteriores ${ }^{18}$, testimonian un entronque que no negaba el propio compositor, al tiempo que reivindicaba la pertenencia de la sonata a una línea evolutiva "natural":

Los tiempos extremos son una lógica consecuencia de la forma de creación que ya había empleado en la 'Introducción, fuga y final' para piano, es decir, una escritura en la que algunos aspectos de la música del barroco hacen su aparición como elementos coordinadores de la forma.

No se trata de un neoclasicismo, sino de una búsqueda en la típica forma del barroco, para encontrar una lógica constructiva a un idioma basado en la serie de doce notas. Este camino lo abandoné por considerarlo cerrado para una evolución natural de mi pensamiento musical. Son, en cambio, los tiempos centrales los que me van a servir para estructurar la siguiente obra, 'Cinco microformas para orquesta'. Considero por tanto esta sonata para violín solo, el arranque de mi actual forma de creación, ya que en ella están presentes el final de una etapa y el principio de la siguiente ${ }^{19}$

Aludía Halffter a esos elementos barrocos como determinantes; por nuestra parte, indique- 


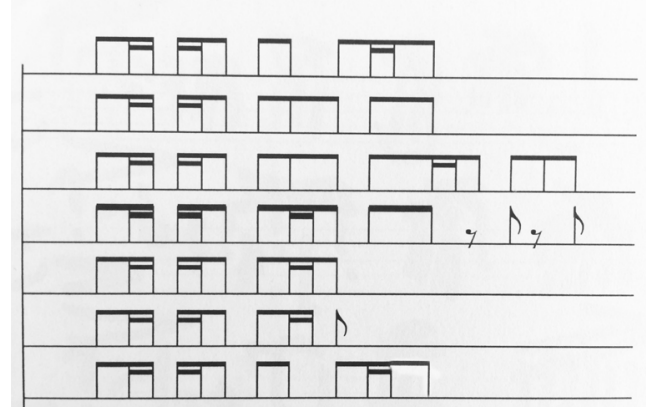

Fig. 2. Evolución rítmica del patrón ostinato de la Sonata para violín solo, de C. Halffter (IV. Finale, cc. 19-33) (Halffter, Cristóbal. Sonata per violino solo. U.E. 13425 LW. London: Universal Edition, 1961)

mos también dos referentes que creemos pertinentes: lejano, el de la Sonata para violín solo op. 31/1 (1924), de Hindemith; más directo, el de la bartókiana Sonata para violín solo Sz. 117 (1944), singularmente su "Presto" final como modelo para el "Finale" halffteriano y su naturaleza rítmica acuciante, fundada en un patrón rítmico -con claros paralelismos con el que aparece en los cc. 84-86 del "Tempo di ciaccona" de la sonata de Bartók- que desarrolla, a modo de tropo por adición, un esquema fijo no retrogradable de ocho unidades de tactus de semicorchea, completado mediante la multiplicación por números primos $\left(5,3^{2}, 3\right.$ y de nuevo 5$)$ de la agrupación binaria inicial y en constante alternancia métrica (fig. 2).

\section{De las 5 microformas a In exspectatione resurrectionis Domini (1959-1962): la con- solidación de una primera práctica de van- guardia}

Apenas un mes después del estreno por Antonio Gorostiaga de la Sonata para violín solo en las salas del Instituto de Cultura Hispánica de Madrid (7 de junio de 1959), Halffter fechaba la versión definitiva de la cuarta de sus 5 microformas para orquesta [op. 24] ${ }^{20}$, primer movimiento completado de una obra que la historiografía musical ha coincidido en señalar como determinante, no solo para la trayectoria personal del compositor, sino para la historia de un incipiente, y breve, serialismo español, tanto por su significación intrínseca como - desde el ángulo de la recepción pública de ese repertorio- por la encendida reacción del auditorio con motivo de sus interpre- taciones por la Orquesta Nacional de España y Odón Alonso en febrero de 1961 (fig. 3). A este propósito, que precisaría una atención específica, traemos a colación solo una de las críticas más ponderadas de esta reposición de las 5 microformas, la del compositor Alberto Blancafort, quien se detenía en el valor de la obra per se sin ocultar los términos del escándalo (y su cercanía personal a Halffter):

Séame permitido, sin embargo, exponer mi opinión personal de que las 'Microformas' constituyen la obra más acabada y personal del autor. Al cálculo más o menos matemático del andamiaje constructivo de la partitura, Cristóbal tiene el acierto de dejarse llevar por su instinto musical y la cualidad de aceptar y asimilar cuantas influencias sean afines a su sensibilidad. Con ello el compositor crea un mundo sonoro personal que se nos hace pronto familiar, por estar ligado, pese a su novedad, a una serie de tradiciones. Desde el punto de vista tímbrico, las 'Microformas' son abundantes en refinadísimas y sutiles bellezas. Su audición tuvo la virtud de caldear el habitual ambiente poco apasionado del Palacio de la Música. En el Monumental fueron tan ruidosas y radicales las muestras de entusiasmo y desaprobación como yo no había visto nunca en este local. Cristóbal Halffter salió cinco veces a corresponder a los aplausos y ruidos; pero, a juzgar por los ánimos, hubiera podido salir y entrar indefinidamente ${ }^{21}$

Otro de los protagonistas de la nueva composición en nuestro país recalcaba en enero de 1960 el camino serial como la vía inexorable de modernización definitiva, previa su asimilación como "algo específicamente nacional":

Puede predecirse la incorporación total de la música española a las corrientes seriales, con lo que sería sustituida la vieja influencia impresionista francesa por una determinante centroeuropea. A este ingrediente activo debe sumarse uno pasivo: el retroceso absoluto de la música nacionalista más o menos enraizada en el folklore ${ }^{22}$

Por su parte, Halffter, en una entrevista poco posterior, se hacía eco de esta perspectiva, al manifestar un similar rechazo del elemento nacionalista -pese a reivindicar el "carácter ibérico" de su creación-, la voluntad de dotar de una dimensión propia al empleo de las técnicas seriales -"mi máxima aspiración es latinizar el serialismo"- y la renuncia a asideros constructivos preconcebidos 
o ajenos al despliegue sonoro, en la pretensión de una "[...] creación pura, sometida únicamente a las necesidades estrictamente musicales" ${ }^{23}$; un objetivo de autonomía referencial sonora prioritario -aunque, como veremos, situado en un horizonte estético en parte discrepante-, a juzgar por los títulos definitivos de cada pieza en la edición de la partitura²4 (I. Tema. Primera variación; II. Segunda variación. Dos contrapuntos; III. Tercera variación. Estructuras verticales y horizontales; IV. Cuarta variación. Ritmos; V. Quinta variación. Variaciones sobre un ritmo serial) y por los comentarios analíticos ya disponibles de la obra ${ }^{25}$.

En espera de mejor ocasión para un proyectado estudio específico sobre las 5 microformas halffterianas, nos centraremos ahora en dos aspectos menos transitados de su 'intrahistoria': su proceso de escritura -y algunas observaciones sobre los materiales de composición conservados en la PSS-SCH- y la relevancia de la obra en la difusión internacional, sobre todo en su vertiente editorial, del catálogo del compositor. Subvencionada por las becas de creación artística de la madrileña Fundación Juan March en su convocatoria de 1959/196026, a la altura de marzo de 1959 habían de ser siete (y no cinco) las 'microformas' constituyentes de la obra, bajo un concepto unitario de gradación de la densidad instrumental-conservado a grandes rasgos en la versión definitiva- que culminaría en el empleo del tutti sinfónico solo en la séptima pieza ${ }^{27}$. Por otra parte, existe en dichos materiales un esquema formal gráfico, no datado, que responde a esta división septenaria, cuyos rasgos básicos acabarían condensados en la redacción final: así, un "Allegretto" inicial, con la exposición del tema de las variaciones por los instrumentos de viento metal; dos subsecciones "Allegro molto", con protagonismo del viento madera y la cuerda, que proceden por canon rítmico directo, invertido y por aumentación; un extenso "Final" en tres subsecciones; y, como séptima pieza, la "Exposición" del tema serial por el tutti orquestal.

A inicios de octubre de 1959, la estructura interna en solo cinco movimientos de la obra ya se había confirmado, según anunciaba Halffter a Alexandre Tansman, su maestro de composición en el segundo curso de 'Música en Compostela' celebrado en verano de ese mismo año28; pero, al mismo tiempo, se presentaba aún una característica que quedaría enmascarada en la versión definitiva a causa de la supresión -salvo en la tercera microforma, "Adagio" - de indicaciones agógicas y su sustitución por puras marcas metronómicas: la conformación absolutamente simétrica de los tempi de cada 'microforma' en torno a ese "Adagio" central: "Allegro molto" - "Allegro non tanto" - "Adagio" - "Allegro non tanto" - "Allegro molto".

Otras informaciones relevantes proveídas por el estudio de los materiales de escritura de la obra merecerían también un comentario más detallado, como la probable derivación de su serie dodecafónica de alturas a partir del estudio de composiciones de Luigi Dallapiccola (expresamente, del Quaderno musicale di Annalibera, 1952) o, y sobre todo de cara a futuras ediciones críticas, interpretaciones y grabaciones de las 5 microformas, las pormenorizadas indicaciones de Halffter -que no se incluyeron en la publicación de la partitura- sobre la elección del instrumentario y ciertos consejos de interpretación de la cuarta microforma, escrita únicamente para percusión y sin duda con el asesoramiento de José María Martín Porrás, quien había estrenado en junio de 1957 los Dos movimientos para timbal y [orquesta de] cuerda [op. 12] del compositor madrileño. Nos interesa, sin embargo, extendernos en otra circunstancia: cómo el análisis conjunto de la correspondencia entre Halffter, Tansman ${ }^{29}$ y Alfred A. Kalmus, responsable de Universal Edition, ilustra de qué modo estas 5 microformas ( $y$, en menor medida, la Sonata para violín solo) fueron decisivas para la adscripción de las partituras halffterianas al catálogo de esa editorial vienesa-londinense y, por tanto, para su circulación internacional.

En efecto, una de las primeras cartas cruzadas entre Tansman y su alumno español confirma que, a fines de septiembre de 1959, el compositor polaco ya había recomendado el nombre de Halffter a su propia editorial, Universal Edition, y que la respuesta de Kalmus aconsejaba el envío para inspección de, precisamente, una "obra orquestal relativamente breve" ${ }^{30}$; sin descartar otras posibilidades -como la de la parisina Eschigin-, tanto Tansman como Halffter tomaron la iniciativa de proponer para su evaluación el "Adagio" central de la obra en curso de composición ${ }^{32}$, algo que el autor madrileño cumplió a fines de octubre de 

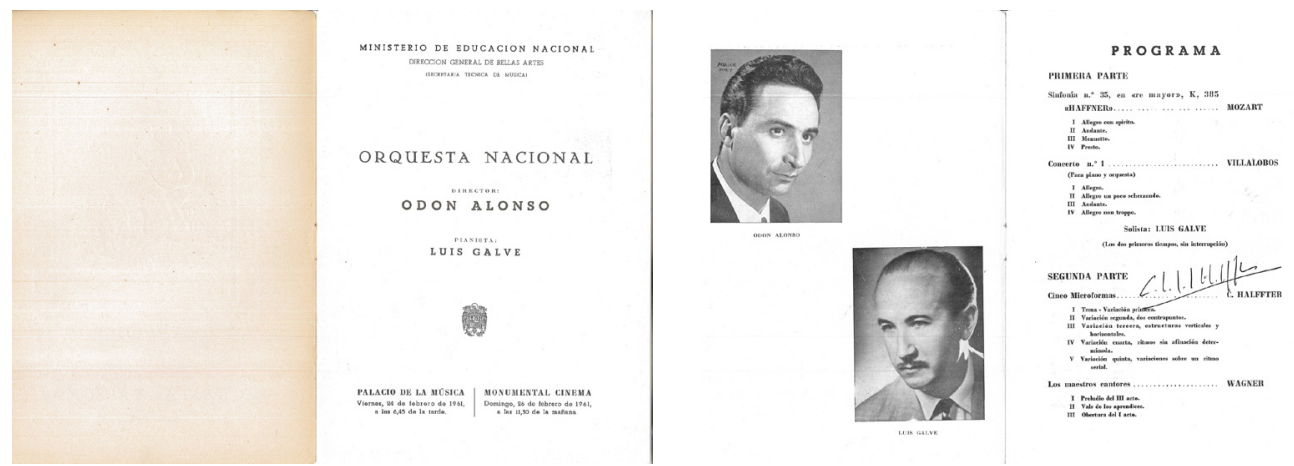

Fig. 3 a y b. Programa de concierto (Madrid, 23 y 25 de febrero de 1961) [5 microformas para orquesta] (Col. Particular)

ese año, ofreciendo una breve descripción del estado de escritura de las 5 microformas ${ }^{33}$ y antes de añadir a la propuesta la Sonata para violín solo ${ }^{34}$. Pese a la aceptación preliminar de Kalmus en noviembre de $1959^{35}$-y a desatender su petición de última hora de contemplar la posibilidad de inclusión en el catálogo de "trabajos folclorísticos, por ejemplo una corta suite sobre canciones populares españolas" ... ${ }^{36}$, sucesivas dilaciones en las reuniones del comité de nuevas admisiones de Universal Edition postergarían un año entero la aceptación definitiva de Halffter en su catálogo editorial ${ }^{37}$, concretada en 1961 y 1962 con la publicación, respectivamente, de la Sonata para violín solo y las 5 microformas para orquesta.

Los pormenores de esta ardua negociación editorial revelan las expectativas puestas por Halffter en su nueva composición orquestal como " puerta de entrada" en el panorama internacional, algo que veremos corroborado en su trayectoria por las salas de concierto a lo largo de la década de 1960. Al mismo tiempo, el compositor parecía sentir la necesidad de una justificación teórica de su reciente deriva creativa y de cómo la "preocupación por la forma" y el "interés por el ritmo" que descubría como constantes en su producción no habían de juzgarse contradictorios con la búsqueda de nuevas y variables soluciones -en este caso, seriales dodecafónicas- para el control de la dimensión melódico-armónica. Así lo postulaba en uno de sus textos estéticos más elaborados, publicado por vez primera en julio de $1961^{38} \mathrm{y}$ en el que, paradójicamente, defendía la necesidad de plegarse a posibles 'desviaciones' de la aplicación estricta de los principios serialistas, en virtud de su supeditación a la consecución de re- sultados sonoros 'bellos' y a una "fuerza superior que nace de la naturaleza de la música" que trae la memoria esa 'necesidad interior' [innere Notwendigkeit] de la estética kandinskiana (fig. 4). Aunque quizá también resonara en esta visión dualista, que parece forzar lo formal en beneficio de lo expresivo heterónomo, la advertencia que su mentor Tansman le transmitiera en febrero de 1960 a propósito de su propia experiencia:

Por lo que respecta a mi pequeño "tema serial", ¡no es en ningún caso un "credo sine qua non"! He empleado los medios que ofrece esta técnica desde hace treinta años $y$, además, he estado personalmente muy en contacto con Schönberg, Berg y Webern. Pero siempre como un [subrayado original] medio de expresión que enriquece nuestro lenguaje y nuestra disciplina, yjamás como un sistema exclusivo, considerando que es útil todo lo que está a nuestra disposición y que nada, dependiendo de cada problema, nos está impuesto ni prohibido. Por tanto, ya no soy el "dodecafónico" que era en 1925, ni tampoco tonal, pues todo "sistema a priori", en mi opinión, no aporta en absoluto la unificación de estilo, sino la aniquilación [subrayado original] de la expresión original. Además, todo sistema restringe el campo expresivo y emotivo de la música, que es, ante todo, una arte acústica y no gráfica. Por mi parte, estoy seguro de que, una vez pasado por la útil disciplina de la serie, llegará por sí mismo a la conclusión de que una técnica particular no es el objetivo, sino que lo es el contenido de invención que reviste ${ }^{39}$

En el difícil intento de equilibrio entre rigor técnico y expresividad autónoma, Halffter encontró un modelo en uno de los compositores que mencionaba Tansman: Anton Webern, ejemplo, 
en sus propias palabras, para la "nueva generación" por su "don altísimo de invención y organización" ${ }^{40}$, en un artículo publicado poco después de la conclusión de las 5 microformas y a propósito de una obra (los orquestales 5 Stücke op. 10 (1911/13) del compositor austríaco) cuya concepción aforística, distribución en cinco piezas e incluso la elección de tempi en torno a uno central lento no es osado en exceso relacionar con la propia composición halffteriana. En el momento de su interpretación en Viena el 6 de abril de 1964, Bruno Maderna (al frente de la Radio-Symphonie Orchester Wien) emparejó las "microformas" de Halffter precisamente con esa weberniana op. 10; y aunque algunas críticas no resistieran la cómoda tentación de relacionar sus "excesos sonoros y rítmicos" con el origen español del compositor ${ }^{41}$, la mayoría de la prensa subrayó el dominio de la técnica sinfónica, la vitalidad y rigor del empleo del lenguaje serial y la brillantez de concepción rítmica de una "música centelleante de fuerte atractivo" ${ }^{42}$.

No era esta audición vienesa la primera vez que las 5 microformas visitaban el extranjero: ya habían sonado antes en París (26 de octubre de 1960) y México D. F. (3 de julio de 1961), dirigidas en ambas ocasiones por el propio Halffter. Con motivo de esa interpretación mexicana -en la que era la primera visita americana del compositor y oportunidad para su encuentro con su tío Rodolfo-, Cristóbal Halffter concedería una entrevista al musicólogo exiliado Otto Mayer-Serra en que resumía, de modo apodíctico, la única vía que, a su juicio, se abría para la consecución de una "música nueva en lenguaje, contenido, forma, técnica, dinámica y sonoridades"43: "Hoy en día, únicamente el sistema serial nos abre la perspectiva de una renovación formal [...] Sólo la serie es capaz de ordenar el caos" $" 4$.

$Y$, sin embargo, que "el caos" permitía otras posibilidades de resolución, más colaborativas que reactivas, ya lo había experimentado Halffter en su labor creadora... En el transcurso de esa misma entrevista, el compositor mencionaba como su obra más reciente una concluida hacía casi cuatro meses ${ }^{45}$ : Formantes (Móvil para dos pianos) [op. 26) (1960/61), su primera incursión en el ámbito de las 'formas abiertas' tan en boga en la vanguardia europea desde 1956/1957, y a partir de los ejemplos de Pierre Boulez (Sonata n. 3 para piano) y Karlheinz Stockhausen (Klavierstück $X I)$.

El dúo pianístico no constituyó la primera opción sopesada por Halffter para su nueva composición: tal vez impelido por la fortuna de semejante formación desde el primer libro de Structures (1952), de Pierre Boulez, y por propuestas más cercanas al Madrid de Halffter, como Móvil I (1957) y Progressus/Móvil II (1959/67), de Luis de Pablo, el músico madrileño acabó desechando, como corroboran los materiales de escritura conservados en la PSS-SCH y algunos testimonios epistolares ${ }^{46}$, varias posibilidades de empleo de diversas formaciones instrumentales de unos diez instrumentos y con un esquema formal bipartito ["Allegro"-"Adagio"], que hasta mediados de enero de 1961 se mantuvieron incorporando el dúo pianístico como núcleo concertante ${ }^{47}$, para eliminar finalmente todo acompañamiento instrumental.

Del mismo modo, la estructura combinatoria establecida en la versión editada de Formantes -a grandes rasgos, el encuadramiento de seis estructuras o "formantes" móviles, cuyo orden queda al arbitrio de los intérpretes, entre dos estructuras fijas, que actúan como introducción o preludio y final o posludio, respectivamente ${ }^{48}$ - también se vio modificada a lo largo de los meses de composición de la obra. No hay duda, por otra parte, de que la escritura de cada uno de los formantes se conservó siempre estricta y que la partitura establecería, en este punto, un respeto absoluto a las indicaciones dinámicas y metronómicas, pero la concepción inicial de Halffter era más radical en cuanto a las posibilidades de organización formal interna: en planteamientos preliminares, se preveían la posibilidad de hasta diez variantes de alguno de los formantes móviles o el dibujo de múltiples trayectorias entre ellos, así como el desplazamiento de las estructuras fijas extremas hacia una posición intermedia.

Halffter se mostraba, en ello, extremadamente consciente de los retos que la "música abierta" planteaba al compositor, si bien desde una postura sin duda estéticamente comedida: para "continuar siendo dueño absoluto de aquello que ha creado", era necesario, a su juicio, 'moderar' la libertad del intérprete en sus ámbitos de elección, como, en marzo de 1961, defendía que sí lograba 

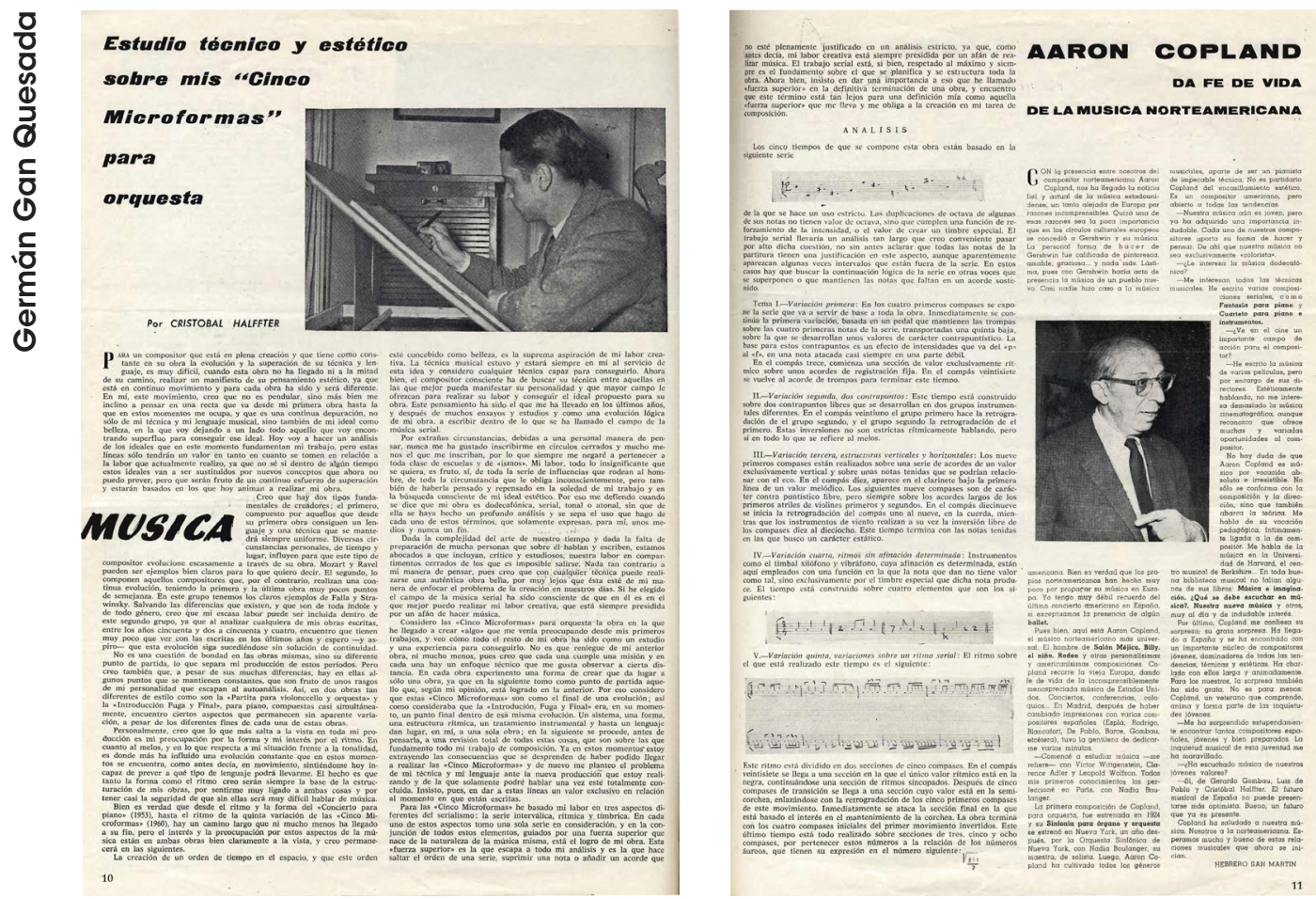

Fig. 4 a y b. Halffter, Cristóbal. 1961. "Estudio técnico y estético sobre mis 'Cinco microformas' para orquesta." La Estafeta literaria 221 (15 de julio de 1961): 10-11.

Stockhausen en el mencionado Klavierstück XI, ejemplo de equilibrio entre flexibilidad formal, direccionalidad macroestructural y control paramétrico ${ }^{49}$; y dos años y medio más tarde mantenía esta postura sin apenas cambios al aceptar los recursos aleatorios como la resolución natural de la búsqueda de soluciones formales post-seriales, siempre que se supeditaran a una concepción estructural de índole superior y no anularan la que consideraba irrenunciable 'paternidad' del compositor sobre su obra ${ }^{50}$. Por utilizar los conocidos términos de Ramón Barce, el concepto aleatorio de Halffter se movía claramente en los márgenes superiores de 'control' del producto sonoro, una actitud que continuaría vigente en su catálogo durante toda la década de 1960 y, especialmente en el campo sinfónico, a lo largo de buena parte de su producción posterior ${ }^{51}$.

Dedicados a Tansman, y tras su estreno privado en el domicilio madrileño del mecenas portugués Duarte Pinto Coelho (21 de marzo de 1962) (fig. 5), Formantes conoció, de manos de los mismos intérpretes -Manuel Carra y María Manuela Caro, esposa del compositor-, su primera audición pública en el Ateneo de Madrid el 17 de mayo de ese mismo año. Apenas tres semanas después, el 6 de junio, Carra y Caro presentaban la obra en el festival anual de la Sociedad Internacional de Música Contemporánea (SIMC), celebrado en Londres, en lo que constituía un paso decisivo en las ambiciones artísticas de Halffter, puesto que era su primera presencia en un foro internacional de tal magnitud ${ }^{52}$; el compositor, sin embargo, no era un desconocido para el público melómano británico, puesto que su Sonata para violín solo había recibido ya en medios ingleses alabanzas por su "vitalmente fascinante" calidad a raíz de su edición ${ }^{53}$ y, aun más, el comentario de su catálogo había encabezado la discusión sobre los integrantes del grupo "Nueva Música" publicada a inicios de año por Arthur Custer en The Musical Quarterly, que señalaba las 5 microformas como el fin de la etapa formativa de Halffter ${ }^{54}$. 


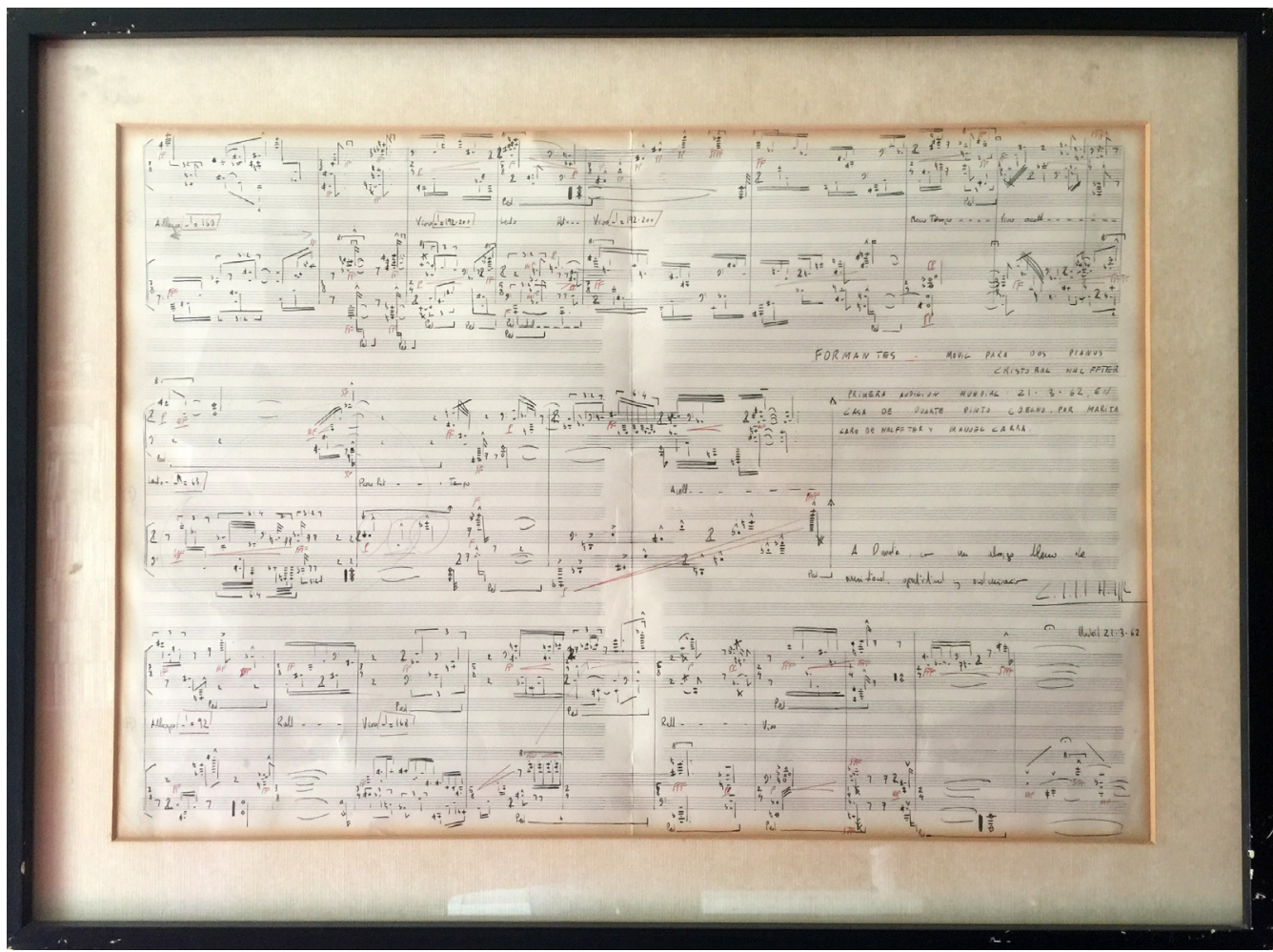

Fig. 5. Doble página de la partitura original de Formantes, dedicada a Duarte Pinto Coelho (Madrid, 21 de marzo de 1962) (Col. Particular)

Con ocasión de esta interpretación londinense de Formantes, Halffter ejerció, de manera excepcional en su carrera, tareas de crítica musical55; más interesantes que sus opiniones, no excesivamente elaboradas, sobre las obras escuchadas en el festival, resulta -al menos para nuestro discurso- comprobar cómo seguía presente en esas críticas la obsesión contradictoria que parece dominar la trayectoria del compositor, y de muchos de sus cogeneracionales en el ámbito de la creación musical española, en estos años de progresiva mayor visibilidad pública: la aspiración a una internacionalización técnica y estética de la música española (por él mismo representada con acentos de retórica suficiencia) que, al mismo tiempo, conservase rasgos nacionales peculiares y diferenciadores que, tal vez, le permitieran un encaje propicio en los círculos restringidos de la 'nueva música' de su tiempo:

Siempre resulta muy difícil el tener que hablar uno de su propia obra, y esto se agrava cuando esta obra ha representado la música española en un Festival de la categoría y trascendencia como el que se ha celebrado hace unos días en Londres. Lo único que puedo decir, sin temor a equivocarme, es que mi obra no ha sido ni peor, ni mejor que las demás, ni más vieja, ni más nueva que las otras, pero sí diferente. Esto quiere decir que la música española está totalmente incorporada a las corrientes de la vanguardia de la música mundial, que nos expresamos con unos medios que son comunes a todos aquellos compositores de la nueva generación que intentan una renovación del lenguaje sonoro para que este esté a la "altura de los tiempos en que vivimos". Pero también quiere decir que nuestra música presenta una visión personal de los problemas, nacida de la fuerza que caracteriza siempre todas las actividades del espiritu eminentemente españolas ${ }^{56}$

Desde la perspectiva de un compositor de vanguardia en 1962, solo faltaba a Halffter superar un escalón más, pero determinante, en la con- 
secución de un status internacional reconocido: la participación -y sobre todo programación-en esos mismos Internationale Ferienkurse de Darmstadt a los que no había podido asistir en 1958 y a los que sí habían acudido en el cambio de década intérpretes como Manuel Carra y Pedro Espinosa o compositores como Ramón Barce, Carmelo Bernaola, Juan Hidalgo, Gonzalo de Olavide y Luis de Pablo. Habría de esperar el músico madrileño a la edición de 1963, precisamente con esos Formantes (22 de julio) y en interpretación del prestigioso dúo conformado por los hermanos Alfons y Aloysius Kontarsky57; y aunque no todo lo allí escuchado le dejó la misma impresión -así, por ejemplo y de modo exclusivamente privado, tan solo pareció convencerle la interpretación de la op. 24 weberniana y del segundo libro de Structures, de Boulez, a diferencia de la tajante opinión peyorativa sobre las obras presentadas por Krzystof Penderecki (Threni) y lannis Xenakis (ST4)-, el compositor reconoció pronto el impacto que el ambiente darmstadtiano había causado en él de cara a su carrera futura, en comunicación epistolar con el responsable de Universal Edition Alfred Schlee:

Darmstadt ha sido para mí una experiencia muy eficaz y un estímulo muy importante para seguir trabajando en una línea de seriedad, de exigencia ante uno mismo y de responsabilidad. Espero mucho de las obras que ahora comienzo a elaborar en las que, no sé si estarán presentes todas las 'modas' oídas en Darmstadt, pero sí, que serán un reflejo fiel de una meditada, profunda y seria postura ante la creación musical de nuestro tiempo ${ }^{58}$

Durante el primer semestre de 1963, Halffter había prolongado su catálogo oficial más allá de Formantes: a inicios de año, había completado su primer encargo internacional de relevancia, la Sinfonía para tres grupos instrumentales (1961/63), que se estrenaría en los Donaueschinger Musiktage el 19 de octubre y que, entre otras características, sofistica el universo tímbrico de las 5 microformas mediante el recurso a la espacialización instrumental y al pensamiento aleatorio; a mediados de junio, daba a conocer la versión inicial de Espejos (1963/64), para cuatro percusionistas y cinta, su primera aproximación -exceptuando anteriores aplicaciones incidentales y en música cinematográfica- a las sonoridades electrónicas ${ }^{59}$. Por su parte, el 13 de abril de 1963 la catedral de Cuenca había presenciado el estreno de su cantata In exspectatione resurrectionis Domini, cuya composición efectiva tuvo lugar entre julio y septiembre del año anterior (y de ahí su inclusión en este texto, próximo a su conclusión) como encargo de la II Semana de Música Religiosa de la ciudad manchega.

Aunque, como indica Jesús María Muneta60, pueda considerarse In exspectatione... la culminación de la música religiosa halffteriana hasta ese momento -con estaciones previas en la Antífona pascual a la Virgen 'Regina coli' [op. 4] (1952) y la Misa ducal [op. 10] (1955/56)-, no se trata sin más de un compendio de pasadas experiencias: es cierto que la introducción de elementos aleatorios en la parte orquestal recoge el interés anterior de Halffter por estos procedimientos, pero, al mismo tiempo, la división de ese orgánico orquestal en grupos bien definidos prefigura la concepción de la mencionada Sinfonía para tres grupos instrumentales, del mismo modo que el empleo de cuatro percusionistas en su plantilla establece una pauta que se mantendrá en la Sinfonía... para expandirse, hasta cinco intérpretes de percusión, en Secuencias (1964) y Symposion (1964/66). Y, por otra parte, el recurso al texto (en este caso, una selección de fragmentos de la liturgia del Sábado Santo) -cuya inteligibilidad se ve favorecida por el tratamiento contrapuntístico de relativa simplicidad, o incluso homofónico, de las partes corales y por la claridad de la escritura melódica de la parte solista de barítono- sugiere una nueva solución al dilema entre rigor estructural del discurso sonoro autónomo y buscada emotividad quasi programática: son la atmósfera expresiva y la semántica textual los elementos que dictan la construcción de clímax dinámicos y de progresión de tempi y que rigen la distribución de densidades sinfónicas y participaciones instrumentales, descritas por el compositor en su comentario de la obra con símiles de naturaleza descriptiva ${ }^{61}$.

\section{A modo de conclusión}

Los escasos cinco años que separan los estrenos de Introducción, fuga y final y de In exspectatione resurrectionis Domini dibujan un arco evolutivo no exento de contradicciones, titubeos y soluciones fallidas -o, cuanto menos, parciales- en la trayectoria de Cristóbal Halffter, 
dominada en ese lustro por una vocación de proyección internacional que comienza, con todo, a verse cumplida con su acceso al mercado editorial de la mano de Universal Edition y con la programación más frecuente de sus composiciones en auditorios foráneos; gracias, en muchas ocasiones, al desarrollo paralelo de su actividad como director de orquesta y al establecimiento de relaciones interpersonales en los círculos de vanguardia musical europeos. Al mismo tiempo, las composiciones de las que nos hemos ocupado en estas páginas establecen también, cada una a su particular manera, el inicio de una 'genealogía' propia dentro del catálogo del compositor: el fundamento matemático de estructuras musicales en las 5 microformas (varias de las cuales recurren para el cálculo de relaciones rítmicas y duración de secciones a la aplicación de la serie de Fibonacci) se prolonga, por ejemplo, hasta Fibonaciana (1969); la introducción de elementos aleatorios controlados en conceptos formales de carácter global de Formantes o de la Sinfonía para tres grupos instrumentales persiste, en la década de 1960, en páginas como Secuencias (1964)62, Antiphonismoi (1967) o, sobre todo, Anillos (1967/68)63; la tensión entre expresividad textual y autonomía sonora se desata en el mencionado Symposion y en la versión sinfónica de los Brecht-Lieder (1967), para culminar en Yes, Speak Out, Yes (1968); y, de extendernos a obras ya compuestas en 1963, la experiencia electrónica de Espejos encuentra frutos mucho más acabados en la segunda mitad de la década, con obras como Líneas y puntos (1966) (fig. 6) o Noche pasiva del sentido (1969/70).

Probablemente, como indicaba el propio compositor muchos años más tarde en un sentido general, nos encontramos ante uno de esos períodos en los que "[...] la técnica queda más en primer plano, antes de eso que podemos llamar 'expresividad'; que no es algo opuesto a la técnica, sino su complemento" "64; una etapa en la que la simple escucha, por no decir el análisis, de muchas composiciones escritas en ella -y nos referimos sobre todo a las 5 microformas para orquesta y a Formantes en la producción halffteriana, pero también a muy buena parte del repertorio de música española de vanguardia "dura" de los años sesenta- puede dejarnos la impresión de que no rebasan el valor de meros testimonios de época sin

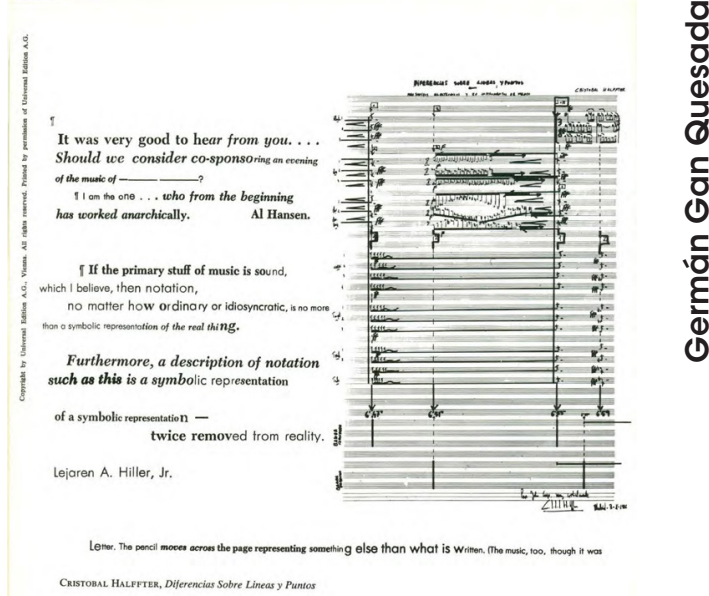

Fig. 6. Halffter, Cristóbal. 1969. "Diferencias sobre Líneas y puntos" (Madrid, 3 de octubre de 1966). Notations, ed. por John Cage y Alison Knowles, s. p. New York: Something Else Press

interés inmanente. A ello contribuye, sin duda, el hiato interpretativo provocado por el abandono, en programaciones y grabaciones, de la gran mayoría de esas obras desde fines de la década de 1960, una situación que, sin embargo, contrasta con su continua mención desde perspectivas puramente históricas, sociológicas o institucionales, sin atenderlas apenas como constructos sonoros y propuestas artísticas. No se trata solo de un déficit de actitud o atención académicas, sino también de una carencia (o de la improbable accesibilidad) de nuevas fuentes primarias cuyo análisis permita esa renovación hermenéutica: por no abandonar el catálogo de Halffter, y como botón de muestra de esta situación, no existe grabación comercial alguna de las 5 microformas, de In exspectatione... o de la Sinfonía para tres grupos instrumentales. Cuando esas 'microformas' suban de nuevo a los atriles de una orquesta en marzo de 202165, habrán pasado más de tres décadas desde su última interpretación, que compartirá ciclo con otras dos composiciones del mismo período presididas por similares inquietudes de renovación, el depabliano Imaginario II (1967) y los Espacios variados (1962), de Bernaola; quizás está llegando por fin el momento de escuchar estas 'viejas' vanguardias con otros oídos y, al mismo tiempo, de releerlas y apreciarlas desde nuevos horizontes técnicos y estéticos... 


\section{NOTAS}

* Este texto ha sido redactado en el marco del Proyecto I+D+i RTI2018093436-B-100 Música y danza en los procesos socioculturales, identitarios y políticas del segundo franquismo y la transición (1959-1978) (Ministerio de Ciencia, Innovación y Universidades).

1 "Spanish music today seems to have entered a period of stagnation". Musicus [seud. de Pablo, Luis de]. 1968. "New Music in Spain." En Twentieth Century Music. Its Forms, Trends and Interpretations, ed. por Rollo H. Myers, 203-214, 203. New York: The Orion Press. Todas la traducciones se deben al autor.

2 Según sostiene García del Busto, José Luis. 1998. "Crónica de vida y obra." En De Volder, Piet. Encuentros con Luis de Pablo, 9-47, 14. Madrid: SGAE-Fundación Autor. Aunque publicado en 1968, el artículo de 'Musicus' debió concluirse hacia 1959 ó 1960, ya que las últimas obras comentadas en él datan de 1958.

3 Delás, José Luis [de]. 1959. "La música después de 1950." El Paso-Boletín 15 (Octubre): s. p. Reproducido en Toussaint, Laurence. 1983. "El Paso" y el arte abstracto en España, 249-256, 256. Madrid: Cátedra.

4 Por ejemplo, los pioneros de Ángel Medina: Medina Álvarez, Ángel. 1996. "Apuntes sobre la recepción de la Música abierta en España." Anuario musical 51: 217-232; Medina Álvarez, Ángel. 2001. "Primeras oleadas vanguardistas en el área de Madrid." Cuadernos de música iberoamericana 8-9: 337-366.

5 Así, sobre Luis de Pablo (López Estelche, Israel. 2013. "Luis de Pablo: vanguardias y tradiciones en la música española de la segunda mitad del siglo XX." Tesis doctoral, Universidad de Oviedo; Añón Escribá, Manuel. 2016. "Constantes estéticas en la música de Luis de Pablo." Tesis doctoral, Universidad de Granada) o Carmelo Bernaola (Moro Vallina, Daniel. 2019. El compositor Carmelo Bernaola (1929-2002). Una trayectoria en la vanguardia musical española. Bilbao: Universidad del País Vasco/Euskal Herriko Unibertsitatea).
6 Por mencionar solo los de carácter biográfico y analítico más acusado: Marco, Tomás. 1972. Cristóbal Halffter. Madrid: Servicio de Publicaciones del Ministerio de Educación y Ciencia - Dirección General de Bellas Artes; Casares Rodicio, Emilio. 1980. Cristóbal Halffter. Oviedo: Servicio de Publicaciones de la Universidad de Oviedo - Departamento de Arte-Musicología; Daschner, Hubert. 2000. Cristóbal Halffter. Spanische Musik auf der Höhe ihrer Zeit. Saarbrücken: PFAU-Verlag; Gan Quesada, Germán. 2005. La obra de Cristóbal Halffter: creación musical y fundamentos estéticos. Granada: Universidad de Granada.

7 Gan Quesada, Germán. 2018. "El universo de la guitarra en la obra de Cristóbal Halffter. Notas para su estudio." Roseta. Revista de la Sociedad Española de Guitarra 13: 6-15, 12-15.

8 Gan Quesada, Germán. 2007. "Tópico folklórico, tradición e innovación en un ballet 'español': Jugando al toro de Cristóbal Halffter." Revista de Musicología XXX, no. 1: 181-206.

9 O de la estrictamente literal con el título del movimiento conclusivo de la Sinfonía n. 2 (1902/03), de Vincent D'Indy, sin ninguna relación ulterior con la obra de Halffter.

10 Halffter, Cristóbal. 1959. "Génesis de una obra." Acento cultural 4 (Febrero): 52-54. Tanto Casares 1980, 70-71, como, con mayor profundidad, Daschner 2000, 26-29, se basan en este texto para sus comentarios sobre la obra.

11 Franco, Enrique. 1960. "Dos obras españolas para piano: la Sonata de Blancafort y las piezas de C. Halffter." Acento cultural 7 (Marzo-Abril): 57-59, 58. Años más tarde, Halffter ofrecería una introducción histórica a la obra de Hindemith, con motivo de la interpretación por F. Goebbels de su Ludus tonalis (Madrid, Instituto Alemán, 11 de mayo de 1964).

12 "[...] un progressiu a la Hindemith", en carta a Joaquim Homs (27 de junio de 1959). Ribé Queralt, Ramon, Pietat Homs Fornesa, eds. 2015. Robert Gerhard. Joaquim Homs. Correspondència, 108. Valls: Cossetània Edicions.

13 Musicus 1968, 207: "[...] the consequences, especially as regards form and timbre, which such a revolution implies".

14 Según consta por carta datada el 26 de marzo de 1959 [PSS-SCH, Korrespondenz, carpeta Edizioni Suvini Zerboni] y por respuesta de Ricordi Milano a su solicitud (28 de abril de 1959) [PSSSCH, Korrespondenz, carpeta Clausetti, Eugenio].

15 "Neue Anwendungsmöglichkeiten des seriellen Prinzips". La ficha de inscripción de Halffter en los cursos de Darmstadt de 1958, con fecha 12 de junio de dicho año, se encuentra en el archivo del Internationales Musikinstituts Darmstadt (IMD-A100936-201517-09. https://www.imd-archiv.de/detail//MDA100396-201517-09?q=cristobal+half fter\&d=\&f\%5Bevent_facet \% 5D\%5B0 $\% 5 D=$ Ferienkurse $+1958 \& p=1 \& s=25 \& \mid$ $=$ list \&0\%5Bscore $\% 5 D=$ desc); $y$, de hecho, su nombre figura entre los alumnos matriculados en el seminario de Krenek (Maurer Zenck, Claudia. 2017. "Hin- und hergerissen, oder: Heimisch im Exil, fremd in der Heimat. Ernst Krenek zwischen den USA und Europa." En Return from Exile - Rückkehr aus dem Exil. Exiles, Returnees and Their Impact in the Humanities and Social Sciences in Austria and Central Europa, ed. por Waldemar Zacharasiewicz y Manfred Prisching, [201]-226, 214 y 225-226. Wien: Austrian Academy of Sciences Press). Como confirma una carta de Manuel Carra a Halffter (21 de octubre de 1958), ni él ni Luis de Pablo acudieron finalmente a la ciudad alemana [PSS-SCH, Korrespondenz, carpeta Carra Fernández, Manuel].

16 Respectivamente, en Marco, Tomás. 1970. Música española de vanguardia, 55. Madrid: Ediciones Guadarrama; y Casares 1980, 72.

17 Así, la titulación inicial de los movimientos primero y tercero según denominaciones genéricas tradicionales: Preludio y Scherzo.

18 Para un comentario analítico sobre la obra, cfr. Daschner 2000, 30-32.

19 [Halffter, Cristóbal]. 1963. "'Sonata para violín solo' de Cristóbal Halffter." (Programa de concierto. Madrid, 11 de diciembre de 1963).

20 Aunque un guion bastante avanzando de la segunda microforma se fecha el 14 de enero de 1959, el 
manuscrito completo y definitivo de la obra indica las siguientes fechas de conclusión de cada pieza: I. 21 de enero de 1960; II. 14 de julio de 1959; III. 19 de agosto de 1959; IV. 9 de julio de 1959; y V. 12 de enero de 1960.

21 Blancafort, Alberto. 1961. "Luis Galve, Odón Alonso y la Orquesta Nacional. Escandalosa acogida al estreno de 'Microformas', de Cristóbal Halffter." Arriba (Madrid), 28 de febrero de 1961.

22 Barce, Ramón. 1960. "La música española ante 1960." Índice 133 (Enero): 12.

${ }^{23} \mathrm{H}$ [ebrero] S[an] M[artín], [Gonzalo]. 1960. "Cristóbal Halffter y la música concreta." La Estafeta literaria 187 (15 de febrero): 6 .

24 Halffter, Cristóbal. 1962. 5 microformas para orquesta. U. E. 13437 LW. London: Universal Edition. Aunque la publicación indica "segunda edición", no existió una edición anterior de carácter comercial, sino solo provisional y de materiales orquestales para las interpretaciones de la obra en 1961.

25 Especialmente, Daschner 2000, 32-35, y, en menor medida, Casares $1980,81-88$

26 Anales de la Fundación Juan March. 1956-1962. 1965, 529 [Madrid: Fundación Juan March]

27 Carta de Cristóbal Halffter a Edizioni Suvini Zerboni (26 de marzo de 1959) [PSS-SCH, Korrespondenz, carpeta Edizioni Suvini Zerboni].

28 Carta de Cristóbal Halffter a Alexandre Tansman (8 de octubre de 1959). Reproducida en Tansman-Zanuttini, Mireille, ed. 2005. Alexandre Tansman. Une voie lyrique dans un siècle bouleversé, pp. 440-441. Paris: L'Harmattan.

29 Hasta el momento, solo Louis Jambou había atendido muy brevemente esta relación epistolar entre Halffter y Tansman; cfr. Jambou, Louis. 2000. "Alexandre Tansman - compositeur - et Andres [sic] Segovia - interprète - ou un en-deçà de l'œuvre musical." En Hommage au compositeur Alexandre Tansman (1897-1986). Actes du Colloque International du 26 novembre 1997 en Sorbonne, ed. por Pierre Guillot, [231]-254, 250-252. Paris: Presses de l'Université de Paris-Sorbonne [reed. sin modificaciones en Jambou, Louis. La musique entre France et Espagne, pp. 307-336, pp. 330-333. Paris: L'Harmattan.

30 Cartas de Alexandre Tansman a Cristóbal Halffter, con fechas 28 de septiembre y 2 de octubre de 1959, respectivamente [PSS-SCH, Korrespondenz, carpeta Tansman, Alexandre]. En esta última, Tansman le transcribía parte de la respuesta de Kalmus a su solicitud: "What I would like to see most would be a comparatively short work for orchestra" (subrayado original).

${ }^{31}$ En carta de Alexandre Tansman a Cristóbal Halffter (25 de octubre de 1959) y en su respuesta (4 de noviembre de 1959), se alude a estas gestiones con la casa editorial parisina [PSSSCH, Korrespondenz, carpeta Tansman, Alexandre]

32 Carta de Alexandre Tansman a Cristóbal Halffter (12 de octubre de 1959) [PSS-SCH, Korrespondenz, carpeta Tansman, Alexandre].

${ }^{33}$ Carta de Cristóbal Halffter a Alfred Kalmus (30 de octubre de 1959) [PSS-SCH, Korrespondenz, carpeta Kalmus, Alfred A.].

${ }^{34}$ Carta de Cristóbal Halffter a Alfred Kalmus (10 de noviembre de 1959) [[PSS-SCH, Korrespondenz, carpeta Kalmus, Alfred A.].

35 Carta de Alfred A. Kalmus a Cristóbal Halffter (22 de noviembre de 1959) [PSS-SCH, Korrespondenz, carpeta Kalmus, Alfred A.], en que también le manifiesta su posible interés por las Tres piezas para flauta sola.

36 Carta de Alfred A. Kalmus a Cristóbal Halffter (12 de octubre de 1960) [[PSS-SCH, Korrespondenz, carpeta Kalmus, Alfred A.]: "Folkloristische Arbeiten, wie z. B. eine kurze Suite ueber spanische Volkslieder [...]". Esta petición surgía, con toda probabilidad, tras la audición por parte de Kalmus de las Cuatro canciones [populares] leonesas (1957), de Halffter, interpretadas en Londres (9 de octubre de 1960) por Victoria de los Ángeles y Gerald Moore.

37 Carta de Alfred A. Kalmus a Cristóbal Halffter (16 de noviembre de 1960) [PSS-SCH, Korrespondenz, carpeta Kalmus, Alfred A.].

38 Halffter, Cristóbal. 1961. "Estudio técnico y estético sobre mis 'Cinco microformas' para orquesta." La Estafeta literaria 221 (15 de julio): 10-11. Este texto, derivado del guion de la conferencia que, bajo el título de "Microformas", pronunció el compositor en el Ateneo de Madrid el 9 de marzo de 1961 dentro del ciclo "Algunos compositores españoles ante su obra", fue reproducido en varias ocasiones en los programas de mano de interpretaciones de las 5 microformas; entre ellas, las yas mencionadas madrileñas de febrero de 1961.

39 Carta de Alexandre Tansman a Cristóbal Halffter (21 de febrero de 1960) [PSS-SCH, Korrespondenz, Carpeta Tansman, Alexandre]: "Pour ce qui est de mon petit 'thème sériel' ce n'est nullement un 'credo sine qua non'! Je me suis servir des moyenes qu'offre cette technique depuis plus de trente ans, ayant été personellemente très lié, en plus, avec Schönberg, Berg et Webern. Mais toujours comme d'un moyen d'expression qui enrichit notre langage et notre discipline, et jamais comme un système exclusif, considérant que tout ce qui est à notre disposition est utilisable, et que rien n'est ni Imposé, ni défendu, suivant chaque problème. Je ne suis donc pas plus 'dodécaphoniste' que je l'étais en 1925, ni moins tonal, car tout 'système à priori' dans mon opinion, n'apporte point l'unification du style, mais l'annihilation d'expression originale. Du plus, tout système rétréçit le champ expressif et émotif de la musique qui est, avant tout une art acoustique, et non graphique. Pour ma part, je suis certain, qu'une fois passé par la discipline utile de la série, vous viendrez de vous même à la conclusion que ce n'est pas une technique particulière qui est le but, mais le contenu inventif qu'elle recouvre".

40 Halffter, Cristóbal. 1960. "Anton Webern. Cinco piezas para orquesta, opus 10." La Estafeta literaria 188 (1 de marzo): 20-21, 21.

${ }^{41}$ Así, el crítico del Kurier vienés, que se refiere a los "klängliche und rhythmischen Exzesse" de la composición, para continuar: "puedo imaginármelo (a Halffter) sentado a gusto en locales flamencos" ("Ich kann mit vorstellen, daß er gerne in FlamencoLokalen sitzt"). Weishappel, Rudolf. 1964. "Stenogramme und Längeres. 
Gestern im Sendessal: 3. Musica-Nova-Konzert under Maderna." Kurier (Wien), 7 de abril de 1964.

42 "[...] sprühende Musik von starkem Reiz". Knessl, Lothar. 1964. "Radio Wien: Internationalizierte 'neue Musik'." Neues Österreich (Wien), 8 de abril de 1964.

${ }^{43}$ Mayer-Serra, Otto. 1961. "Sólo la 'serie' es capaz de ordenar el caos." Audiomúsica 42 (1 de julio): 20-23, 23.

44 Ibidem, 22.

45 Los materiales de composición de Formantes (PSS-SCH) están fechados entre el 13 de diciembre de 1960 y el 17 de marzo de 1961.

46 Como sendas cartas, ambas fechadas el 13 de diciembre de 1960, a Alfred Kalmus y Alexandre Tansman [PSS-SCH, Korrespondenz, carpeta Kalmus, Alfred A.; Korrespondenz, carpeta Tansman, Alexandre].

47 Así aluden a ella Franco, Enrique. 1960. "Un gran recital de Luis Galve en París. Noticias y conciertos." Arriba (Madrid), 18 de diciembre de 1960; y Hebrero San Martín, Gonzalo. 1961. "Noches de Madrid." Madrid, 16 de enero de 1961.

48 Para un comentario analítico sobre la obra, cfr. Marco 1970, 130-131; Casares 1980, 88-93; y Daschner 2000, 36-38.

49 Halffter, Cristóbal. 1961. "Klavierstück-XI, de Stockhausen." La Estafeta literaria 212 (1 de marzo): 14-15.

50 Halffter, Cristóbal. 1963. "Cabe la creación en la música abierta." La Estafeta literaria 274 (14 de septiembre): 5.

51 Barce, Ramón. 1965. "Control, supercontrol, infracontrol." Atlántida IV, no. 15 (Mayo-Junio): 305-315. Reproducido en Barce, Ramón. 2009. Las palabras de la música. Escritos de Ramón Barce, ed. por Juan Francisco de Dios Hernández y Elena Martín, 160170. Madrid: ICCMU.

${ }^{52}$ Las 5 microformas para orquesta habían sido seleccionadas por la sección española de la SIMC para su interpretación, en representación nacional, en el festival del año anterior, celebrado en Viena, pero fueron descartadas por el jurado final de programación.
53 "[...] vitally exciting". Dickinson, Peter. 1962. "Solo Violin or Viola." The Musical Times 103, no. 1431 (Mayo): 340.

54 Custer, Arthur. 1962. "Contemporary Music in Spain." The Musical Quarterly XLVIII, no. 1 (Enero): 1-18, 7. En 1965, Custer reeditaría este texto con pequeñas modificaciones, que en el caso de Halffter prolongan el comentario hasta 1963 (Custer, Arthur. 1965. "Contemporary Music in Spain." En Contemporary Music in Europe, ed. por Paul Henry Lang y Nathan Broder, 4460, 45-49. New York: Schirmer Books).

${ }^{55}$ Así, Halffter, Cristóbal. 1962. "El Festival de Música Contemporánea de Londres." Arriba (Madrid), 20 de junio de 1962; y Halffter, Cristóbal. "Festival de Música Contemporánea de Londres." Arriba, 20 de junio de 1962.

56 Halffter, Cristóbal. 1962. "Londres, Festival de Música Contemporánea-España presentó 'Formantes' de Cristóbal Halffter." Triunfo, 2 (16 de junio): 31.

57 Para la consulta de las obras programadas en los cursos de Darmstadt en sus dos primeras décadas de actividad, cfr. Borio, Gianmario y Hermann Danuser, eds. 1997. Im Zenit der Moderne. Die Internationalen Ferienkurse für Neue Musik Darmstadt 1946-1966. Geschichte und Dokumentation in vier Bänden, III, 513ss. Freiburg: Rombach.

${ }^{58}$ Carta de Cristóbal Halffter a Alfred Schlee (3 de agosto de 1963) [PSS$\mathrm{SCH}$, Korrespondenz, Carpeta Schlee, Alfred].

59 Para un análisis de Espejos, cfr. Martín Nieva, Helena. 2011. "Espejos para 4 percusionistas y cinta magnética (1963) de Cristóbal Halffter: contextualización y análisis gráfico." Espacio sonoro 52. http://espaciosonoro.tallersonoro.com/2011/09/28/ espejos-para-4-percusionistas-y-cintamagnetica-1963-de-cristobal-halfftercontextualizacion-y-analisis-grafico-helena-martin-nieva/. Sobre su concepción en el marco de las interrelaciones entre vanguardia musical y pictórica durante el período, cfr. Gan Quesada, Germán. 2017. "Plastic Frames for New Sounds. Spanish Avant-garde Music and Abstract Painting in the Mid-Franco Regime (1957-1963)." En Music and Figurative
Arts in the Twentieth Century, ed. por Roberto Illiano, 323-345. Turnhout: Brepols.

60 Muneta, Jesús M. a. 1978. Cuenca 1962. Renacimiento de la música religiosa española, p. 364. Cuenca: Instituto de Música Religiosa. Sin bien son útiles las páginas dedicadas por Daschner a esta cantata (Daschner 2000, 7374), es la monografía de Muneta (pp. 97-109 y 409-421) la que ofrece una referencia más acabada sobre la escritura de la obra, así como un interesante comentario analítico.

${ }^{61}$ Como "[...] el mundo de sonoridades gélidas" que pretende evocar el inicio de la obra, a cargo de los instrumentos de viento ([Halffter, Cristóbal]. 1963. "In exspectatione resurrectionis Domini." En II Semana de Música Religiosa. Cuenca. Abril, 1963. Programa general, s. p. [Madrid: Ministerio de Educación Nacional - Dirección General de Bellas Artes]). Lamentablemente, la única grabación disponible (aunque no comercial) de In exspectatione..., con toda probabilidad recogida en su segunda interpretación (Madrid, 18 de mayo de 1963), apenas permite apreciar en la escucha, por el grado de saturación dinámica y falta de relieve tímbrico de su toma de sonido, esa intención (AECIDBiblioteca Digital 5SON-1151. http:// bibliotecadigital.aecid.es/bibliodig/i18n/ consulta/registro.cmd?id=2429). $Y$ aun menos "el sabor austero de nuestro románico" que en In exspectatione... distinguía Rodolfo Halffter... (Alejandro, F. 1963. "Sonata para tres Halffter y un piano. Velada con Ernesto, Rodolfo y Cristóbal a propósito de Don Manuel de Falla." Mundo hispánico 184 (Julio): 3942, 42).

62 Para el contexto sociopolítico e ideológico de Secuencias, cfr. Contreras Zubillaga, Igor. 2019. "El Concierto de la Paz (1964): Three Comissions to Celebrate 25 Years of Francoism." En Composing for the State. Music in Twentieth-Century Dictatorships, ed. por Esteban Buch, Igor Contreras Zubillaga y Manuel Deniz Silva, [168]-186. London y New York: Routledge.

63 " [...] yo encierro la macroforma de la obra y dejo en libertad la microforma", afirmaba Halffter en una entrevista a finales de 1965 ("Entrevista con 
Cristóbal Halffter". 1965. SP 272 (12 de diciembre): 47-53, 51).

64 Armendáriz Moreno, David. 2001. Una conversación con Cristóbal
Halffter, 37. Pamplona: Servicio de Publicaciones de la Universidad de Navarra.

65 Madrid, 12 de marzo de 2021

(Orquesta Nacional de España / Rubén
Gimeno). Orquesta y Coro Nacionales de España. http://ocne.mcu.es/programacion/focus-festival-02. 
Entre la necesidad y el azar. Nuevos datos para el estudio de la obra de Cristóbal Halffter

\section{REFERENCIAS}

\section{Discografía}

Formantes

Alberto Rosado, Juan Carlos Garvayo (pianos)

VERSO VRS 2063 'Cristóbal Halffter. Música para piano(s)' (2008)

Introducción, fuga y final

Alberto Rosado (piano)

VERSO VRS 2063 'Cristóbal Halffter. Música para piano(s)' (2008)

Sonata para violín solo

Emma Alexeeva (violín)

Instituto Cervantes de Bremen NIPO 503-04-003-

7 'Polifonía de compositores / Komponistenpolyphonie', 2 (2004)

\section{Bibliografía}

Alejandro, F. "Sonata para tres Halffter y un piano. Velada con Ernesto, Rodolfo y Cristóbal a propósito de Don Manuel de Falla." Mundo hispánico 184 (Julio, 1963): 39-42.

Anales de la Fundación Juan March. 1956-1962. Madrid: Fundación Juan March, 1965.

Añón Escribá, Manuel. "Constantes estéticas en la música de Luis de Pablo." Tesis doctoral, Universidad de Granada, 2016.

Armendáriz Moreno, David. Una conversación con Cristóbal Halffter. Pamplona: Servicio de Publicaciones de la Universidad de Navarra, 2001

Barce, Ramón. "La música española ante 1960." Índice 133 (Enero, 1960): 12.

Barce, Ramón. "Control, supercontrol, infracontrol." Atlántida IV, no. 15 (Mayo-Junio, 1965): 305-315 (Reproducido en Barce, Ramón. Las palabras de la música. Escritos de Ramón Barce, ed. por Juan Francisco de Dios Hernández y Elena Martín, 160-170. Madrid: ICCMU, 2009).

Blancafort, Alberto. "Luis Galve, Odón Alonso y la Orquesta Nacional. Escandalosa acogida al estreno de 'Microformas', de Cristóbal Halffter." Arriba (Madrid), 28 de Febrero de 1961.

Borio, Gianmario, and Hermann Danuser, eds. Im Zenit der Moderne. Die Internationalen Ferienkurse für Neue Musik Darmstadt 19461966. Geschichte und Dokumentation in vier Bänden. Freiburg: Rombach, 1997.

Casares Rodicio, Emilio. Cristóbal Halffter. Oviedo: Servicio de Publicaciones de la Universidad de Oviedo - Departamento de Arte-Musicología, 1980.

Contreras Zubillaga, Igor. "El Concierto de la Paz (1964): Three Comissions to Celebrate 25 Years of Francoism." In Composing for the State. Music in Twentieth-Century Dictatorships, ed. by Esteban Buch, Igor Contreras Zubillaga and Manuel Deniz Silva, 168-186. London and New York: Routledge, 2019.

Custer, Arthur. "Contemporary Music in Spain." The Musical Quarterly XLVIII, no. 1 (Enero, 1962): 1-18. https://doi.org/10.1093/mq/XLVIII.1.1

Custer, Arthur. "Contemporary Music in Spain." In Contemporary Music in Europe, ed. by Paul Henry Lang and Nathan Broder, 44-60. New York: Schirmer Books, 1965. https://doi. org/10.1093/mq/LI.1.44

Daschner, Hubert. Cristóbal Halffter. Spanische Musik auf der Höhe ihrer Zeit. Saarbrücken: PFAU-Verlag, 2000.

Delás, José Luis [de]. "La música después de 1950." El Paso-Boletín 15 (Octubre, 1959): s. p. (Reproducido en Toussaint, Laurence. "El Paso" y el arte abstracto en España, 249-256. Madrid: Cátedra, 1983).

Dickinson, Peter. "Solo Violin or Viola." The Musical Times 103, no. 1431 (Mayo, 1962): 340. https://doi.org/10.2307/948839

"Entrevista con Cristóbal Halffter." SP 272 (diciembre, 12, 1965): 47-53.

Franco, Enrique. "Dos obras españolas para piano: la Sonata de Blancafort y las piezas de C. Halffter." Acento cultural 7 (Marzo-Abril, 1960): 57-59. 
Franco, Enrique. "Un gran recital de Luis Galve en París. Noticias y conciertos." Arriba (Madrid), 18 de diciembre de 1960.

Gan Quesada, Germán. La obra de Cristóbal Halffter: creación musical y fundamentos estéticos. Granada: Universidad de Granada, 2005. https://doi.org/10.2307/20798019

Gan Quesada, Germán. “Tópico folklórico, tradición e innovación en un ballet 'español': Jugando al toro de Cristóbal Halffter." Revista de Musicología XXX, no. 1 (2007): 181-206. https://doi.org/10.2307/20797873

Gan Quesada, Germán "Plastic Frames for New Sounds. Spanish Avant-garde Music and Abstract Painting in the Mid-Franco Regime (1957-1963)." In Music and Figurative Arts in the Twentieth Century, ed. by Roberto Illiano, 323-345. Turnhout: Brepols, 2017.

Gan Quesada, Germán. "El universo de la guitarra en la obra de Cristóbal Halffter. Notas para su estudio." Roseta. Revista de la Sociedad Española de Guitarra 13 (2018): 6-15.

García del Busto, José Luis. "Crónica de vida y obra." En Encuentros con Luis de Pablo, Piet De Volder, 9-47. Madrid: SGAE-Fundación Autor, 1998.

Halffter, Cristóbal. "Génesis de una obra." Acento cultural 4 (Febrero, 1959): 52-54.

Halffter, Cristóbal. Introducción, fuga y final. UME 19507. Madrid: Unión Musical Española, 1959.

Halffter, Cristóbal. "Anton Webern. Cinco piezas para orquesta, opus 10." La Estafeta literaria 188 (Marzo, 1, 1960): 20-21.

Halffter, Cristóbal. Sonata per violino solo. U.E. 13425 LW. London: Universal Edition, 1961.

Halffter, Cristóbal. "Klavierstück-XI, de Stockhausen." La Estafeta literaria 212 (Marzo, 1, 1961): 14-15.

Halffter, Cristóbal. "Estudio técnico y estético sobre mis 'Cinco microformas' para orquesta." La Estafeta literaria 221 (Julio, 15, 1961): 10-11.
Halffter, Cristóbal. 5 microformas para orquesta. UE 13437 LW. London: Universal Edition, 1962.

Halffter, Cristóbal. "Londres, Festival de Música Contemporánea-España presentó 'Formantes' de Cristóbal Halffter." Triunfo 2 (Junio, 16, 1962): 31.

Halffter, Cristóbal. "El Festival de Música Contemporánea de Londres." Arriba (Madrid), 20 de junio de 1962.

Halffter, Cristóbal. "Festival de Música Contemporánea de Londres." Arriba (Madrid), 12 de julio de 1962.

[Halffter, Cristóbal]. "In exspectatione resurrectionis Domini." En // Semana de Música Religiosa. Cuenca. Abril, 1963. Programa general, s. p. [Madrid: Ministerio de Educación Nacional Dirección General de Bellas Artes], 1963.

Halffter, Cristóbal. "Cabe la creación en la música abierta." La Estafeta literaria 274 (Septiembre, 14, 1963): 5.

[Halffter, Cristóbal]. "'Sonata para violín solo' de Cristóbal Halffter." (Programa de concierto. Madrid, 11 de diciembre de 1963).

Halffter, Cristóbal. In exspectatione resurrectionis Domini. UE 13646 LW. London: Universal Edition, 1967.

H[ebrero] S[an] M[artín], [Gonzalo]. "Cristóbal Halffter y la música concreta." La Estafeta literaria 187 (Febrero, 15, 1960): 6.

Hebrero San Martín, Gonzalo. "Noches de Madrid." Madrid, 16 de enero de 1961.

Jambou, Louis. "Alexandre Tansman - compositeur - et Andres [sic] Segovia - interprète - ou un en-deçà de l'œuvre musical." En Hommage au compositeur Alexandre Tansman (18971986). Actes du Colloque International du 26 novembre 1997 en Sorbonne, ed. par Pierre Guillot, 231-254. Paris: Presses de I'Université de Paris-Sorbonne, 2000.

Knessl, Lothar "Radio Wien: Internationalizierte 'neue Musik'." Neues Österreich (Wien), 8 de abril de 1964.

López Estelche, Israel. "Luis de Pablo: vanguardias y tradiciones en la música española de la 
Entre la necesidad y el azar. Nuevos datos para el estudio de la obra de Cristóbal Halffter

segunda mitad del siglo XX." Tesis doctoral, Universidad de Oviedo, 2013.

Marco, Tomás. Música española de vanguardia. Madrid: Ediciones Guadarrama, 1970.

Marco, Tomás. Cristóbal Halffter. Madrid: Servicio de Publicaciones del Ministerio de Educación y Ciencia - Dirección General de Bellas Artes, 1972.

Martín Nieva, Helena. "Espejos para 4 percusionistas y cinta magnética (1963) de Cristóbal Halffter: contextualización y análisis gráfico." Espacio sonoro 52 (2011). http:// espaciosonoro.tallersonoro.com/2011/09/28/ espejos-para-4-percusionistas-y-cinta-magnetica-1963-de-cristobal-halffter-contextualizacion-y-analisis-grafico-helena-martin-nieva/

Maurer Zenck, Claudia. "Hin- und hergerissen, oder: Heimisch im Exil, fremd in der Heimat. Ernst Krenek zwischen den USA und Europa." In Return from Exile - Rückkehr aus dem Exil. Exiles, Returnees and Their Impact in the Humanities and Social Sciences in Austria and Central Europa, ed. by Waldemar Zacharasiewicz and Manfred Prisching, 201226. Wien: Austrian Academy of Sciences Press, 2017. https://doi.org/10.2307/j.ctt1xp3w37.19

Mayer-Serra, Otto. "Sólo la 'serie' es capaz de ordenar el caos." Audiomúsica 42 (Julio, 1, 1961): 20-23.

Medina Álvarez, Ángel. "Apuntes sobre la recepción de la Música abierta en España." Anua- rio musical 51 (1996): 217-232. https://doi. org/10.3989/anuariomusical.1996.i51.317

Medina Álvarez, Ángel. "Primeras oleadas vanguardistas en el área de Madrid." Cuadernos de música iberoamericana 8-9 (2001): 337366.

Moro Vallina, Daniel. El compositor Carmelo Bernaola (1929-2002). Una trayectoria en la vanguardia musical española. Bilbao: Universidad del País Vasco/Euskal Herriko Unibertsitatea, 2019.

Muneta, Jesús M. ${ }^{a}$. Cuenca 1962. Renacimiento de la música religiosa española. Cuenca: Instituto de Música Religiosa, 1978.

Musicus [seud. de Pablo, Luis de]. "New Music in Spain." En Twentieth Century Music. Its Forms, Trends and Interpretations, ed. por Rollo H. Myers, 203-214. New York: The Orion Press, 1968.

Ribé Queralt, Ramon, y Pietat Homs Fornesa, eds. Robert Gerhard. Joaquim Homs. Correspondència. Valls: Cossetània Edicions, 2015.

Tansman-Zanuttini, Mireille, ed. Alexandre Tansman. Une voie lyrique dans un siècle bouleversé. Paris: L’Harmattan, 2005.

Weishappel, Rudolf. "Stenogramme und Längeres. Gestern im Sendessal: 3. Musica-NovaKonzert under Maderna." Kurier (Wien), 7 de abril de 1964. 